\title{
What can isotopes tell us about the atmospheric $\mathrm{H}_{2}$ cycle?
}

\author{
MARIA Elena Popa ${ }^{1}$, Dipayan PAUl ${ }^{2}$, Christof JANSSEN $^{3}$, \\ FREDERIK FELIUS ${ }^{4}$, FABIAN EdUARdo TAPIA ROdRIGUEZ ${ }^{5}$, \\ THOMAS RÖCKMANN ${ }^{6}$ \\ ${ }^{1}$ Utrecht University, Institute for Marine and Atmospheric \\ Research Utrecht (IMAU), m.e.popa@uu.nl \\ ${ }^{2}$ University of Groningen, Centre for Isotope Research (CIO), \\ d.paul@rug.nl
}

${ }^{3}$ Sorbonne Université, Observatoire de Paris, Université PSL, CNRS, LERMA-IPSL, Laboratoire d'Etudes du Rayonnement et de la Matière en Astrophysique et Atmosphères, christof.janssen@upmc.fr

${ }^{4}$ Utrecht University, Institute for Marine and Atmospheric Research Utrecht (IMAU), frederikfelius@gmail.com

${ }^{5}$ Utrecht University, Institute for Marine and Atmospheric Research Utrecht (IMAU), f.e.tapiarodriguez@uu.nl

${ }^{6}$ Utrecht University, Institute for Marine and Atmospheric Research Utrecht (IMAU), T.Roeckmann@uu.nl

At a mole fraction of about $500 \mathrm{ppb}$, molecular hydrogen $\left(\mathrm{H}_{2}\right)$ is the second most abundant reduced gas in the atmosphere after methane. It is important for atmospheric chemistry, and an indirect greenhouse gas due to its reaction with $\mathrm{OH}$, which increases the lifetime of methane. Atmospheric $\mathrm{H}_{2}$ is produced by incomplete combustion processes, together with $\mathrm{CO}$, and from atmospheric oxidation of $\mathrm{CH}_{4}$ and non-methane hydrocarbons. $\mathrm{H}_{2}$ is also emitted into the atmosphere by microbial sources (fermentation, $\mathrm{N}_{2}$ fixation) and by geologic sources (seeps, volcanoes). The main sinks for atmospheric $\mathrm{H}_{2}$ are uptake by soil microbes and reaction with $\mathrm{OH}$ radicals.

The isotopic composition of $\mathrm{H}_{2}(\delta \mathrm{D})$ has been used to investigate its atmospheric budget, based on the fact that main sources, sinks and chemical processes of $\mathrm{H}_{2}$ have specific isotopic signatures. Partially due to these studies, the atmospheric $\mathrm{H}_{2}$ cycle is currently relatively well understood.

We will present an overview on the current knowledge on the atmospheric $\mathrm{H}_{2}$ isotopic budget, and on the remaining questions, information gaps, and potential for future studies. We will also introduce the newly developed clumped isotope measurements $(\Delta \mathrm{DD})$, and will discuss their potential for studying atmospheric, (micro)biologic and geologic processes. 